\title{
THE INFERENTIAL CONSTRUCTION
}

\author{
Gerald P. Delahunty ${ }^{1}$
}

\section{Introduction}

This paper analyses the textual and pragmatic properties of a sentence form which has attracted little scholarly attention, presumably because of its infrequent occurrence. The following provides two examples of the construction:

(1) It's not that he hates the press the way Nixon did, it's just that he is insensitive to the press' role in our society. (L.A. Times 12/18/83)

The construction is of interest first because it appears to be universal; second because an analysis of its occurrence and interpretation illustrates some of the activities performed by participants in discourse, the resources that language and languages make available for those activities, the principles that govern the interactions between language and context, and the ways in which speakers can manipulate those resources for narrative purposes; and third, because its successful analysis provides support for the principles and assumptions used to account for it. I will argue that the subordinate clause of the construction represents an interpretation of its local discourse context, which in turn licenses the derivation of a range of locally specific inferential connections between the context and the clause. These characteristics can be accounted for by Grice's cooperative principle (CP) and maxims of conversation.

I have been looking for examples of this sentence type for several years, but have so far collected only 85 . The infrequency of the construction is matched by the infrequency with which it is mentioned by linguists. I know of only seven references to it, and in three of these the construction is mentioned merely as an appendix to the discussion of another sentence form. Delahunty (1982) mentions it as a type of cleft sentence, a position endorsed by Declerck (1988, 1992), (but see Collins 1991); Quirk et al. (1985) mention it in a footnote to their discussion of obligatory extrapositive constructions; Kuno (1973) discusses the Japanese analogue, the no

\footnotetext{
${ }^{1}$ My thanks are due to Jim Garvey, Dick Kitchener, Karl Krahnke, David Lindstrom, Cynthia Mesh-Ferguson, and Marna Shillman for discussion on the topics of this paper. The errors which remain are, of course, due to my not taking their good advice. A preliminary version of this article appeared in the Kansas Working Papers in Linguistics, Vol. 15, No. 1, 1990, under the title 'Inferentials: The story of a forgotten evidential.'
} 
desu construction. ${ }^{2}$

The form had no generally used name, and I eventually settled on inferential. The reason for this name will, I trust, become clear as we proceed.

The present study is based on a corpus of instances of the construction along with as much prior and following context as seems relevant. The instances are taken from a range of text types. Most come from written sources, both fiction and nonfiction, literary, scholarly, and journalistic; a few were spoken, in both radio editorials and informal conversation. Although the current work focuses on the English inferential construction, the construction exists in a number of other languages and may be universal. ${ }^{3}$

I begin by providing a brief grammatical overview of the inferential construction, describing how it can be modified by negation, modals, adverbs, and complementizers. Then, I describe the distribution of the construction in texts. Third, I describe the construction's various contextualized interpretations. Fourth, I briefly discuss negative inferentials. Finally, I relate the interpretation of inferentials to Grice's notion of implicature.

\section{Grammatical overview of the inferential construction}

Inferentials, in English, are sentences in which a tensed subordinate clause is embedded as the complement of a form of $b e^{4}$ whose subject is expletive it. I will refer to the embedded clause of an inferential, corresponding to that he hates the press the way Nixon did and that he is insensitive to the press' role in our society in (1), as "the clause," and the part to which the clause is subordinate as "the matrix," corresponding to it's (not) (just) in (1).

${ }^{2}$ According to the October 1988 LSA Bulletin, Karina Wilkinson was scheduled to read a paper on 'The "It is not that ..." Construction.' Unfortunately I have been unable to obtain a copy of this.

${ }^{3}$ The construction occurs in at least the following languages: Finnish, French, German, Modern Hebrew, Hungarian, Irish, Italian, Japanese, Korean, Mandarin, Portuguese, Russian, and Spanish. For discussion of the construction in these languages my thanks are due to Paola Malpezzi-Price (French, Italian), Roger Gilmore and Laura Gatzkiewicz (Spanish), Jon and Barbara Thiem, Roland Wolff, and Ron Walker (German), Tom Mark (Hungarian), Zev Bar-Lev (Hebrew), David Argoff and Kaija Wilson (Finnish), Mrs. Gaughran (Irish), Emanuela Mengozzi, Flaminia Cervesi, and David McCobb (Italian), Charles Miracle (Mandarin Chinese), and W. Mary Kim (Korean, Japanese). It appears that we are not dealing with just an areal feature of Western European languages and others, like Hebrew, which are heavily influenced by them.

${ }^{4}$ Declerck (1992) claims that the be of inferentials and clefts is "specificational" in that it specifies a value for a variable. The inferential variable is derived pragmatically from the context and the clause represents its value. Thus a specificational sentence The bank robber is John Thomas answers the question Who is the bank robber (Declerck 1988: 6). However the analogous discourse created from inferentials is ill-formed: What isn't it only It isn't only that I'm nosey. In fact wh-questions created by questioning the clause of an inferential seem to allow only an echo interpretation. It appears, therefore, that it is insufficient simply to classify inferentials as specificational sentences. 
That the it subject of the inferential matrix is expletive, that is, nonreferential and devoid of semantic import, is easily demonstrated. It cannot be questioned (2), or replaced by a referring expression (3):

(2) *What is not only that I am nosey?

(3) ${ }^{*}$ That/this is not only that I am nosey.

From a linguistic universals point of view, it is reasonable to predict that any language which allows either expletive or zero subjects, has a copula, and has subordinate tensed clauses will possess the inferential construction. Moreover, if pragmatic principles of interpretation such as Grice's (1975) CP and maxims and Sperber and Wilson's (1986) principle of relevance are indeed universal, then the construction will have very similar interpretations in all languages that have it. And this is in fact the case.

The construction allows a number of elaborations in the matrix that are textually and pragmatically significant.

The entire inferential structure may be (and in actual use, very often is) modified by adverbs such as perhaps:

(4) Perhaps, it is that women in Ireland are not a form of prayer? (Gogarty 1968: 59)

The matrix may include adverbs such as only, just, and simply:

(5) It was just that it was raining. (Irving 1978: 213-4)

These adverbs can be negated (6), and the complementizer that is optional (7) and (10):

(6) It isn't only that I'm nosey. (P. Cowell e-mail message 4/19/93)

(7) "Oh, it's I'm not pretty enough." (Donohue transcript no. 03120, cited in Kies 1988)

The matrix may also include modals (only may, could, and might occur in my corpus) and negation:

(8) It may be that he lacks some forms of imagination. (Wilder 1987: 174)

(9) It is not that one fears treachery. (Murdoch 1975: 43)

(10) It couldn't be he'd be goin' in it agin. (sic) (Somerville and Ross 1977: 264)

Modals and negation in inferentials may occur in either or both the matrix and the clause, making possible scope relations and interpretations distinct from those in simple sentences: 
(11) a. It may be that I will have tasks for you as cruel as those the Great Mother has laid on me. (Bradley 1982: 136)

b. *I may will have tasks for you as cruel as those the Great Mother has laid on me.

The construction allows the omission of redundant matrix modals, etc. in a text in which a series of clauses are coordinated, as in:

(12) Conceivably some other factor, not well accounted for in the model, is delaying or counteracting the warming. It might be that the heat capacity of the oceans is larger than current models calculate, that the sun's output has declined slightly or that volcanoes have injected more dust into the stratosphere than is currently known, thereby reducing the solar energy reaching the ground. (Schneider 1989: 76)

The matrix It might be in (12) is followed by three coordinated clauses, each of which is in the scope of the modal might, which appears only once in the sentence. If the information in the clauses were expressed in a form other than the inferential, the modal would have to be repeated in each clause. The inferential structure thus allows an elegant and parsimonious parallelism.

Relatedly, it allows modals, negation, and adverbs to be positioned so that the entire clause is within their scope, including any negation or modals within the clause. Consider:

(13) a. [It] is not that what is denied must first have been asserted. (Horn 1989: 47)

b. What is denied must not first have been asserted.

In (13a) the negator takes scope over the modal; in the normalized form, (13b), the reverse occurs, with consequent differences in interpretation.

In (14) the inferential matrix provides the sole position in which only can modify the clause and carry the intended contrast with extraordinary:

(14) Caesar understood well the propitiatory nature of sacrifice amongst the Gauls, but of course there was nothing extraordinary in this custom in Gaul, or in the wider Celtic domain; it was only that the Celts had retained archaic practices once also at home in Italy, as in Greece, but now long outmoded. (Powell 1983: 180)

Of my 85 examples, 23 are positive and unmodalized (two of these are questions ); 12 are positive and modalized; and 50 are negative. Five of my examples are modified by external adverbs: Two each by perhaps and if, and one by thus. Twenty examples are internally modified by adverbs: Five by only, nine by just, three by simply, and three by (not) so much. 


\section{The distribution of inferentials}

I begin discussion of the functions of inferentials by examining their distributions in texts. Negative inferentials have the clearest distributional patterns, so I start with them.

The textual patterns in which negative inferentials occur can be described in the following taxonomy. The most striking pattern is what I call a "tandem inferential," consisting of a negative inferential followed by and contrasting with a positive one:

(15) It was not that I felt we had to avoid the Winters at that moment; it was just that it was raining. (Irving 1978: 213/4)

The second pattern might be called an "embedded tandem," because it contains a single matrix with (at least) two embedded clauses, which contrast with each other on some dimension:

(16) [I]t is not that what is denied must first have been asserted, or that positive facts are more real or more basic than negative ones, but simply that knowledge of a positive fact counts for more than knowledge of a negative one. (Horn 1989: 47)

In this example the first two clauses are within the scope of the matrix negation; the third clause is outside of the scope of the negation, but nonetheless is a complement of $i t$ is.

The third pattern consists of a negative inferential followed by a positive, non-inferential sentence introduced by a contrastive conjunction, typically but:

(17) It is not that mamma cares about it least in the world, but I know it is taken notice of by many persons. (Austen 1980 [1818]: 47)

The two parts of this type of inferential sequence may be separated from each other by considerable distances, as illustrated by the two italicized sentences in:

(18) "It is not that I would fear discovery," says he interrupting. "I have never done any serious disservice to either one - at least nothing they would be likely to know of. And even if they should have cause to mistrust me, I am Sir William Cecil's man, and he has been a patron to them both. But - you should understand this well enough and without knowing too much - there would be questions. There would be, if only for the sake of friendship and good manners, a delay I cannot afford. (Garrett 1983: 173)

The final pattern consists of a negative inferential followed immediately by a positive sentence:

(19) It is not that the model is wrong; there is just not enough evidence 
propuset te candate it. (Maliory i989: 253)

In each of these cases, the negative inferential denies some proposition relevant to the context, while the following sentence asserts an alternative proposition with the same relationstip to the context.

Positive inferentials occur in more varied circumstances. Many occur as the second of two contrasted propositions. Some of these occur as second parts of tandem inferentials, as in (15). Others follow negative, non-inferential constructions, of which the following example is particularly interesting:

(20) I remember that as a little maiden when I was unhappy, when I was chidden by my mother or my teachers, or (a) when Uther - rarely noticed me to disapprove of me, $[\ldots]$.

(b) Not that Uther was ever unkind to me; (c) it was simply that he bat no particular incest in a girl child. My mother was always at the conter of his heart, (Bradley 1982: 108)

I have marked the parts of this sequence as $(a, b, c)$, where (a) is the context that triggers the denial or negation; (b) is the negative construction; and (c) is the positive inferential.

In (b) note the position of not and the form of the clause in its scope. ${ }^{5}$ The clause is subordinate in form but there is no overt matrix clause in which it is embedded and substituting It was not that Lther was ever unkind to me for (b) does not alter the text's well-formedness or its interpretation."

Some positive inferentials follow assertions for which they provide reformulations or reinterpretations (as 1 discuss in more detail below):

(21) He had got past the stage of reason, even his power of mocking at himself was dead, or perhaps it was that there seemed no longer anything that could be mocked at. (Somerville and Ross 1977: 209/10)

These should not be taken as an exhaustive list of the contexts which precede positive inferentials. It is not possible to provide a complete characterization of those contexts. This is because speakers may interpolate an inferential wherever they feel the need to expand upon what they have just said - either to explain it, or reinterpret it, or deny an inference derivable from it. The textual positions at which

\footnotetext{
5 Hungarian negative inferentials can be of this $10 \mathrm{rm}$ - negator followed by a subordinate clause - with no copula or cxpletive in the matrix.

'Declerck (1992) argues that the Not that construction is not inherently specificationai, although he concedes that it can be uscu specificatonally - as in (20) - "if the context contains a variahle." He does not idenity the variable scy ired for the specificational reading of the not that construction in (20)). hut claims that the construction "seves to clarify the relevance of the preceding speech act" (in 9). Given the problems inherent in applying speech act theory to texts such as tloose from which this data is drawn, we could reasonably substitute "piece of text" for "specech act." This of course is very ciose to how I am claiming that the inferential works. I do agree with Deckerck that not ihat and it is not that constructions are not always interchangeable.
} 
the speaker will feel these urges are unpredictable. They are not distinguishable as "contain[ing] a variable" as Declerck (1992) claims. In fact, texts "contain" indefinite numbers of potential "variables." However, many of these sequences may be analysed as composed of three parts. The first part consists of a context which prompts a denial from the speaker; ${ }^{7}$ the second (which may be a negative inferential) rejects a proposition as either not true or not locally relevant; and the third (positive inferential) introduces a proposition which contrasts with the second in being presented by the speaker as true or relevant, or provides the narrator's reasons for rejecting the proposition in the second part. In all cases the interpretation of the inferential requires reference to the local context.

\section{Interpretations of the inferential construction}

In this section I consider the range of meanings displaved by the inferential construction in context and demonstrate that the interpretation of an inferential in context is indeterminate. I claim that the range of meanings represents a natural class. I end this section by considering the roles that the inferential plays in discourse inferencing.

\subsection{Possibility and reflection}

Quirk et al. (1985: 1392) in the footnote in which they reter to it, claim that the construction may be 'used for expressions of possibility and (especially) for reflective questions.' Their (constructed) examples are:

(22) a. It may be that she no longer trusts you.

b. Could it be that you left the hevs in your office?

Notice that both of these contain modals and that the second is a question. In contrast, the two inferentials in my corpus whose matrix clauses are positive, declarative, and contain neither modals nor adverbs do not indicate possibility. The inferential in (23) makes a categorical assertion:

(23) A problem like this gentleman talked about so openly might be just a normal pattern for him, and that couple would feel better if that woman knew it was his normal pattern, she might find it much easier to accept than if she thought, 'Oh, it's I'm not pretty enough.' (Donohue transcript no. 03120, cited in Kies 1988)

Example $(20 \mathrm{c})$, which contains an adverb, asserts that Uther Pendragon had no particular interest in a girl child. These examples suggest that Quirk et al.'s choosing modalized forms misled them and that the form itself does not express possibility.

\footnotetext{
${ }^{7}$ The terms 'speaker' and 'hearer' are intended to include writers and readers as appropriate.
} 
Nonetheless, the form is quite compatible with the expression of possibility, even in declaratives, as the modalized form in (24) shows:

(24) It may be that you have received report of her death from other sources. It may also be true - and we pray that it will be so - that by the time this letter is safe in your hands, her servants will have been set free. (Garrett 1983: $140^{8}$

As I noted earlier, an inferential may be modified by an adverb such as perhaps, thus providing another means of indicating possibility, as in (21) and:

(25) 'He groans when a really good-looking girl meets him. The prettier the worse it takes him. Sometimes he's damned rude.'

'Perhaps it is that women in Ireland are not a form of prayer?' (Gogarty 1968: 58-9)

Reflection is distinct from possibility. It is the process of attempting to interpret some phenomenon. Reflecting may involve asking questions, as in:

(26) Morgause sat on the floor, leaning her head against Viviane's lap, and Igraine saw that the sulky eyes were filled with tears. She has us all in her hand. How can she have such power over us all? Or is it that she is the only mother Morgause has ever known? She was a grown woman when Morgause was born, she has always been mother, as well as sister, to both of us. Their mother, who had been too old for childbearing, had died giving birth to Morgause. (Bradley 1982: 10-11. Italics in original; emphasis added.)

It can also involve drawing inferences, either categorically, as in (23), or tentatively, as in (25). The inferential construction may represent an interpretation, reflection, or conjecture about an issue relevant to the local context. Its mood, modals, or adverbs indicate the degree of certainty with which the interpretation is proposed.

\subsubsection{Reinterpretations/reformulations}

The inferential clause may also represent a reinterpretation or reformulation of an immediately preceding piece of text, more or less tentatively proposed.

${ }^{8}$ Declerck (1992: 207ff) claims that the sentence italicized in (24) is not an inferential but "the extraposed version of that you have received report ... may be [true]; this appears, amongst other things, from the fact that the next sentence begins with it may also be true that ..." It seems to me that replacing the inferential with Declerck's paraphrase, extraposed or not, subtly but significantly, changes the meaning (and well-formedness) of the text. I have checked this intuition with several colleagues (all native speakers of English, though not all linguists). All agreed that the inferential and its true congener are not substitutable in this context. 
(27) He had got past the stage of reason, even his power of mocking at himself was dead, or perhaps it was that there seemed no longer anything that could be mocked at. In spite of his knowledge of the world the position had an aspect that was so serious and beautiful as to overpower the others, and to become one of the mysteries of life into which he had thought himself too cheap and shallow to enter. (Somerville and Ross 1977: 209/10)

In this instance the inferential may be seen as an alternative formulation of the character's state of mind. Moreover, the narrator, by using an inferential and introducing the inferential with perhaps, indicates a limitation on her understanding of the character whose emotions she is describing.

\subsection{Explanations/accounts}

Perhaps the most frequent use of the inferential is to suggest an explanation for whatever circumstances are under discussion. This interpretation occurs amongst all three types, positive unmodalized, modalized, and negative inferentials.

The inferential in (23) is an explanation for the couple's sexual difficulties. The inferential in (25) is a tentatively proposed explanation for 'why European women are utterly without interest for' the author's friend: The autobiographer, Oliver Gogarty, is discussing his friend McLoren's sexual difficulties with one of his 'informants.' McLoren as a young man stationed with the British army in India apparently had sexual relations with a sacred temple courtesan ('a form of prayer' in traditional Indian culture), which were of such intensity and duration that 'European women are utterly without interest' for him. The inferential invites us to infer that McLoren's sexual problems are to be explained by the assumption that Irish women are not a form of prayer. The adverb perhaps and the question mark indicate that the inference is tentative and reflective.

The negative inferential in (28) rejects $I$ did not think of it or desire it as explanations for Wentworth's not writing to Anne Elliot:

(28) 'Tell me if, when I returned to England in the year eight, with a few thousand pounds, and was posted into the Laconia, if I had then written to you, would you have answered my letter? would you, in short, have renewed the engagement then?'

'Would I!' was all her answer; but the accent was decisive enough. 'Good God!' he cried, 'you would! It is not that I did not think of it, or desire it, as what would alone crown my other success. But I was proud, too proud to ask again.' (Austen 1980: 233)

That the inferential can convey an explanatory inference is confirmed by the fact that when the sentence beginning The explanation was . . in (29a) is replaced by an inferential, as in (29b), the two versions of the text are well-formed and synonymous. 
(29)a. In England a new ruling element had displaced much of the existing landholding class, but had been content to divert to itself the labour and produce of the indigenous rural population. When the Normans had expanded into Wales, however, they had established new communities, which came to be known as 'Englishries', in the valley floors, while confining the Welsh inhabitants, by and large, to the uplands. The explanation was, not that the Normans were more hostile towards the Welsh than towards the Anglo-Saxons, but rather that Welsh rural society, with its pastoral emphasis, was not geared to the satisfactory working of arable land. (Frame 1981: 77)

(29)b. It was not that the Normans were more hostile towards the Welsh than towards the Anglo-Saxons, [...].

The difference between the versions is that in the original (29a) it is made explicit that the propositions in the italicized subordinate clauses are to be interpreted as an explanation for the differences between the Norman colonizations of England and Wales. This interpretation is left implicit in the adapted version (29b).

The claim that the clause of an inferential sentence may be interpreted as an explanation for some situation or event is further supported by Kuno's account of the Japanese no desu construction. He claims that no da (informal), no desu (polite), and no de aru (formal writing) can be "roughly translated as it is that" (1973: 223). Desu and its variants are copulas and no is a nominalizing particle. Kuno (1973: 223, no. 1) presents the following pair of examples without and with no desu:
$(30)$
a. Kaze o hiita
cold drew
'I've caught a cold'
b. Kaze o hiita no desu
'(It) is that I have caught a cold'

Kuno translates the majority of his examples of the no desu construction as 'The explanation for $X$ is that S.' (Although in an earlier section (p. 202) he translates them as 'It is the case that S.') For example:

(31) Kaze o hikimasita. Ame ni hurarete nureta no desu
cold drew rain $\quad$ fallen-being got-wet
'I have caught a cold. (Lit.) The explanation for my having caught a
cold is that I was rained on and drenched.' (Kuno 1973: 224, no. 3a)

Kuno discusses interrogative forms of the no desu construction and translates them as requests for the hearer's explanation of some situation. $\underline{\mathrm{Ka}}$ is an interrogative particle.

(32) Kaoiro complexion bad sick

'You don't look well. Is the explanation for your not looking well that 
you are sick?' (Kuno 1973: 225, no. 4a)

In a number of his examples Kuno adds 'or evidence' to the gloss of the construction. For example:

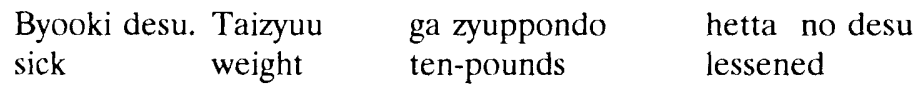

'I am sick. The explanation (or evidence) for my being sick is that I have lost ten pounds.' (Kuno 1973: 226, no. 6a)

Some of these Japanese examples can be felicitously translated into English using the inferential construction. For example:

(34) You don't look well. Is it that you are ill?

(35) I caught a cold. It's that I was caught in the rain and drenched.

(36) ?I am ill. It is that I have lost ten pounds.

The Japanese no desu construction seems to have a somewhat different and larger range of interpretations than the English inferential. It may be that the Japanese construction has conventionalized the interpretation of explanation or evidence. This is consistent with the fact that it contrasts directly with the kara desu construction, which seems to have the conventional interpretation of "it is because..." For example:

Kaze o hikimasita. Ame ni hurarete nureta kara desu. cold drew rain by fallen-being wet-got

'I have caught a cold. It is because I was rained on and drenched.' (Kuno 1973: 226, no. 5)

Further, the no desu construction can be used either to provide an explanation (or evidence) for what has been said or for what has been observed. In other words it does not require a prior linguistic context. The interrogative form particularly seems to be able to occur without one, for example:

(38) Dokoka e iku no desu ka?

somewhere go

'(I see that you are preparing to go out.) Is the explanation for this that you are going somewhere?' (Kuno 1973: 225, no. 4c)

It is unlikely that an English speaker, upon seeing someone preparing to go out, would say 'Is it that you are going somewhere?' rather than 'Are you going somewhere?' or 'Where are you going?' In this context the no desu construction marks the information in the clause as an interpretation of its context and thus may provide an indirect way of asking where the addressee is going or why they are leaving. Indeed, Kuno (1973: 233) suggests that "[i]n the immediate environment in which the speaker has made some observation, questions about the observation without using the no desu construction are often out of place. For example, in talking to a girl who is crying the (a) sentences are out of place: 

a. $\quad$ Naite-imasu ka?
Are you crying?
*Naze naite-imasu ka?
Why are you crying?
b. Naite-iru no desu ka?
Is it that you are crying?
Naze naite-iru no desu ka?
Why is it that you are crying?"

Kuno offers no explanation for why the (a) questions are out of place. Perhaps it is because they do not mark the girl's crying as an interpretation, unlike the two (b) questions, which do, thereby adding a degree of indirectness and politeness. Or perhaps the no desu construction has grammaticalized the explanation interpretation.

Notice of course that 'Is it that you are crying?' is infelicitous in English in this context, presumably because English speakers do not normally treat what they directly observe as an interpretation, even for politeness' sake.

As Kuno does not discuss modifications to the no desu construction analogous to the English adverbs, modals, and negation, it is impossible at this stage of our understanding of these constructions to be certain of how similar they are in Japanese and English. We can, however, note that the tensed clause in inferentials is in subject position, and that no expletive occurs in these sentences in Japanese (or Korean). These constructions may be used to make assertions that implicate cause and explanation. And indeed the English examples discussed here translate straightforwardly into Japanese. For example, (40) translates It's that I'm not pretty enough.

$$
\begin{array}{ll}
\text { Watashi-ga } & \text { kiree-de-nai-kara } \\
\text { I-SM } & \text { pretty-is-NEG-since }
\end{array}
$$

na-no-desu

is-COMP-is ${ }^{9}$

Closely related to explanations are reasons and causes.

\subsubsection{Reasons}

In (41), the clause is interpreted as a reason for him being cruel to her.

(41) Perhaps, if she had not been so frightened and rebellious in those days, she might have seen that he was eager to please her then too. He had not been cruel to her, or if he was, it was only that he seemed to know little of women's bodies and how to use them. (Bradley 1982: 24)

${ }^{9}$ I am grateful to W. Mary Kim of the U.S. Foreign Service Institute for translating several of the English examples into Japanese and Korean and for her comments on this construction in those languages (personal communication). I am, of course, entirely responsible for the interpretation of her comments represented in this paper. 


\subsubsection{Causes}

In (23) the clause, 'I'm not pretty enough' represents the cause of 'his problem.' (42) three potential causes of the delay in global warming are proposed in the three coordinated inferential clauses.

(42) If the observed temperature increase really is a greenhouse warming and not just "noise" - a random fluctuation - one might account for the disparity in various ways. Perhaps the models are simply twice too sensitive to small increases in greenhouse gasses, or perhaps the incomplete and inhomogeneous network of thermometers has underestimated the global warming. Conceivably some other factor, not well accounted for in the models, is delaying or counteracting the warming. It might be that the heat capacity of the oceans is larger than current models calculate, that the sun's output has declined slightly or that volcanoes have injected more dust into the stratosphere than is currently known, thereby reducing the solar energy reaching the ground. (Schneider 1989)

\subsection{Conclusions}

The clause may represent a conclusion drawn from the context.

(43) Lichardus' model is a variant of a broader explanation of the cultural change seen throughout both Northern and Central Europe in the Late Neolithic. [Extensive discussion of the shortcomings of the model.] It is not that the model is wrong; there is just not enough evidence proposed to evaluate it. (Mallory 1989: 253)

In (43) the inferential invites the inference that the conclusion to draw from all of the counter evidence adduced is not that the model is wrong, rather there is just not enough evidence to evaluate it. Beyond this we might add that given all the counter evidence that the author presents, a reader might be forgiven for concluding that the author believes that the model is wrong.

\subsubsection{Results/consequences}

Closely related to conclusions are results and consequences.

(44) Someone - Rubinstein, maybe - once said, when asked if he believed in God: "Oh, no, I believe . . . in something much bigger." And someone else - was it Chesterton? - said that when men stop believing in God, it isn't that they then believe in nothing: They believe in 
everything. (Eco 1989; 620) ${ }^{10}$

In (44) the inferential licenses the inference that the result of men stopping believing in God is not that they then believe in nothing.

\subsection{Relevant alternative comparisons/contrasts}

The clause, especially when the matrix contains just or only, may represent an alternative comparison or contrast to one expressed in the local context.

(45) 'Do you leave Kent on Saturday?' said she.

'Yes - if Darcy does not put it off again. But I am at his disposal. He arranges the business just as he pleases.'

'And if not able to please himself in the arrangement, he has at least great pleasure in the power of choice. I do not know any body who seems more to enjoy the power of doing what he likes than $\mathrm{Mr}$. Darcy.'

'He likes to have his own way very well,' replied Colonel Fitzwilliam. 'But so we all do. It is only that he has better means of having it than many others, because he is rich, and many others are poor. I speak feelingly. A younger son, you know, must be enured to self-denial and dependence.' (Austen 1813 [1963]: 153/4)

In (45) Fitzwilliams' inferential proposes an interpretation of Darcy's behavior or personality that contrasts with Eliza Bennett's, namely that Darcy is richer than many others and so can indulge himself more than they can.

The inferential in (46) expresses an alternative interpretation of the historical facts that contrasts with the interpretation suggested in the immediately prior text.

(46) It would be a mistake, nevertheless, to describe the Irish Church from the sixth century on as a monastic Church. There were bishops throughout Ireland who carried out functions specific to them alone. The fact that there was no late Roman diocesan structure which could be taken over by the Church was not just the case in Ireland; it was evident in all areas outside the boundaries of the Roman Empire. It is just that Ireland was the first country in Western Europe to feel the full impact of these circumstances. (Richter 1988: 61-2)

\subsection{Indeterminacy of interpretation}

Many of these. examples can be entered under several different interpretive

${ }^{10}$ Example (44) is a translation of the original Italian, which has the following inferential corresponding to the italicized English: non è che non credano piu a nulla (Eco 1988: 492). Note the null subject and the other lexical and syntactic elements characteristic of inferentials. 
categories. What this means is that we cannot be sure of our interpretation of the sentences in their contexts; that is, we cannot be certain that the implicatures we derive are actually the ones intended by the speaker. This of course is exactly as Grice predicted (1975: 58):

"Since to calculate a conversational implicature is to calculate what has to be supposed in order to preserve the supposition that the cooperative principle is being observed, and since there may be various specific explanations, a list of which may be open, the conversational implicatum in such cases will be disjunction of such specific explanations, and if the list of these is open, the implicatum will have just the kind of indeterminacy that many actual implicata do in fact seem to have." (My italics.)

For example, (23) It's I'm not pretty enough. . . can be interpreted as a reason for, or a cause of, or an explanation for, or an interpretation of the man's pattern or problem. We have no way of knowing just which of these possibilities is intended by the speaker. Indeed, there is no reason to assume that the speaker intended any specific one of them, as opposed to simply prompting all and leaving it to the hearer to make a choice (or not).

More significantly, we can view all of these categories as representing a single natural class: They all represent aspects of interpretation. So the inferential always represents an interpretation of the local context. Its precise interpretation as an explanation, reflection, etc. depends upon its particular context. Indeed the range of particular implicatures seems to be limited to those which have to do with interpretation. To reflect on, explain, or identify the consequences of some situation (or text) is to interpret it. By analysing the inferential as representing an interpretation of its local context, we can account naturally for this limitation.

\subsection{The roles of the inferential construction in discourse inferencing}

I assume that the interpretation of discourse by its participants is a process of deriving inferences - from the language used and its interaction with its context. In this section I will briefly consider in more general terms the roles played by the proposition expressed by the clause of the inferential construction in the interpretation of discourse. This proposition can function as either a conclusion or a premise.

If the inference represents a conclusion, then it is one that can be derived from the immediately prior text, either alone or in conjunction with implicated premises or bridging assumptions. The conclusion also can be affirmed, qualified, or denied. Example (47) is a clear case of an inferred conclusion.

(47) Lichardus' model is a variant of a broader explanation of the cultural changes seen throughout both Northern and Central Europe in the Late Neolithic. . . [Paragraph continues detailing problems with Lichardus' model.] It is not that the model is wrong; there is just not enough evidence pioposed to evaluate it. (Mallory 1989: 253) 
The problems attributed by Mallory to the Lichardus model along with the assumption that the enumeration of a model's problems are usually sufficient warrant to conclude that (the author thinks that and expects the reader to conclude that) the model is wrong. The author rejects this conclusion and postpones evaluation of the model.

If the inference represents a premise (usually a minor one) then the propositions represented by the (immediately) prior text, or derivable from it, can be deduced from the inferential proposition in conjunction with other, usually implicated (rather than overtly stated) premises or bridging assumptions. Inferences interpreted as premises are often, though by no means solely, interpreted as explanations, causes, or reasons. The premise can be affirmed, qualified, or denied. Example (48) represents an inference interpreted as a premise.

(48) 'Tell me if, when I returned to England in the year eight, with a few thousand pounds, and was posted into the Laconia, if I had then written to you, would you have answered my letter? would you, in short, have renewed the engagement then?

'Would I!' was all her answer; but the accent was decisive enough. 'Good God!' he cried, 'you would! It is not that I did not think of it, or desire it, as what would alone crown my other success. But I was proud, too proud to ask again. (Austen 1980 [1818]: 233)

From the text prior to the inferential we can derive the assumption that Wentworth did not write to ask Anne Elliot to renew their engagement. 'I did not think of it, or desire it' represents a (minor) premise from which, with other readily available assumptions, Wentworth's not writing to ask would follow, and thereby explain why he hadn't written. Wentworth summarily rejects this explanation, and provides an alternative ('I was proud, too proud to ask again'). ${ }^{11}$

\section{Negative inferentials}

Because they do not entirely parallel their positive counterparts, inferentials with a negated matrix require a brief separate comment. We should expect negative inferentials simply to deny the inferences licensed by their positives, and for the most part this is how they function. Clearly, negative inferentials can reject the truth

${ }^{11}$ The inferencing can be laid out as the following syllogism:

If Wentworth did not think of it, or desire it, then he would not write.

Wentworth did not think of it, or desire it.

Therefore Wentworth did not write.

The proposition derived from the clause of an inferential may be entertained either as a premise or as a conclusion, or both:

If Wentworth did not write then he did not think of it, or desire it.

Wentworth did not write.

Therefore Wentworth did not think of it, or desire it. The indeterminacy of the role played by the proposition is a further source of indeterminacy in their interpretation. My thanks to Jim Garvey for discussion on this topic. 
of the information in the clause:

(49) "Nance was sayin' Lambert was gone to Dublin again, but what signifies what the likes of her'd say; it couldn't be he'd be goin' in it agin and he not home a week from it." (sic) (Somerville and Ross 1977: 264)

However, they may reject, not the truth, but the relevance of an assertion or an assumption at the point in the discourse at which they occur:

(50) On principle I usually avoid introducing my friends and acquaintances to each other. It is not that one fears treachery, though of course one does. What human fear is deeper? But endless little unnecessary troubles usually result from such introductions. ${ }^{12}$ (Murdoch 1975: 43)

Similarly, the negative inferential in (47) is compatible with either the model being right or being wrong. Its function is to forestall the reader's inference that the author's litany of the model's inadequacies leads to the conclusion that it is wrong.

Negative inferentials may also deny an inference which would provide a plausible explanation relevant in the context. In (50) the negative inferential rejects the proposition that the narrator fears treachery as the explanation for his reluctance to introduce his friends and acquaintances to each other, a perfectly plausible explanation for his behavior, and an inference that might be made by any reasonable audience. The sentence immediately following concedes this fear. And the third sentence provides the explanation that the narrator wants the audience to accept.

A negative inferential may also deny a plausible interpretation of, or extrapolation from, its context, in the following case, the extrapolation that demon lovers are usually grossly cruel:

(51) It was ... as if she had died long before and come back to me as a demon lover. Demon lovers are always relentless, however kind in life. And it was sometimes as if I could 'remember' Christian's kindness, though all now was spite and demonry. It was not that she was usually, though she was sometimes, grossly cruel. (Murdoch 1975: 91-2).

Only one of my collection of negative inferentials contains a modal, (49) above. The negative takes scope over the modal and we can paraphrase (49) as the negation of a possibility:

(52) It is not possible that he would be going there again.

\footnotetext{
${ }^{12}$ Replacing the inferential in this text with a sentence such as It is not the case that one fears treachery renders the text contradictory. This supports my contention that the inferential is specialized in function and contrasts with sentences such as those with predicates such as 'true' or 'the case' in the matrix.
} 
Many of the inferentials in the corpus, both positive and negative, contain matrix adverbs, typically only, just, or simply. These limit the domain of a contrast. In (45), the contrast between Darcy and 'we all' is initially proposed to be that he likes his own way, but is subsequently limited to his merely being richer than the others, and so better able to afford to indulge himself.

In examples which contain both matrix adverbs and negation, the adverb falls within the scope of the negative. When the adverb is only, the exhaustiveness of the inference is denied. The following passage asserts that Anne Elliot could never accept Mr. Elliot not only because her feelings were adverse to him but also because her judgment was against him:

(53) She never could accept him. And it was not only that her feelings were still adverse to any man save one; her judgment, on a serious consideration of the possibilities of such a case, was against Mr. Elliot. (Austen 1980[1818]: 152)

When the adverb is just or simply, the denial may be either of exhaustiveness or of a limitation of the domain of contrast:

(54) 'I wish, I wish she hadn't met Arnold.'

'You're very attached to Arnold, aren't you?'

'Yes.'

'It's not just that you care what he thinks?'13

'No.' (Murdoch 1975: 117)

So, there is a general, though not perfect, parallelism between positive and negative inferentials. The negative denies the various inferences licensed by the positive. Typically, negative inferentials occur in the context of contrasting claims, most clearly exemplified in the tandem constructions. We can reasonably interpret the pattern as: 'The inference to draw from (the utterance) of this expression is not that $p$; rather it is that $q$.' In this respect inferentials are akin to repairs in conversation.

Many negated inferentials raise the issue of what prompts the inference rejected by the speaker. In some cases, e.g. (49), the inferential clause merely rejects

${ }^{13}$ Declerck (1992: 221, fn 8) paraphrases this inferential as "the nature of your feelings for Arnold" is not just that you care what he thinks?, a paraphrase which is hardly grammatical and certainly not consistent with his analysis. He claims (p.220) that the expressions that replace the expletive $i t$ are "automatically taken from the group reason/cause/explanation/interpretation," a claim which cries out for explanation. Clearly the nature of your feelings for Arnold does not fit naturally into this class. The current analysis suggests a paraphrase such as the following, which fits the text better: I am not to interpret your agreeing that you are very attached to Arnold to mean just that you care what he thinks?

In fact, Declerck's analysis is not nearly restrictive enough. There are many nouns that form a natural semantic class with reason, explanation, etc,, which can appear in the copular structure ' $N P$ is that', and which express a notion whose contents can be specified by a thatclause, c.g. evidence (see my discussion of Kuno's analysis), fact, allegation, forecast, prediction, position, but which do not appear to figure in the interpretation of inferential it is (not) that sentences. This limitation follows naturally from the current analysis. 
a proposition expressed in the prior sentence. But most cases are not so straightforward. Some propositions are derived from generally held beliefs, others from stereotypes. The inferential in (18) derives from the assumption that spies fear discovery; that in (55) represents an inference based on the assumption that rich people who live 'not immodest' lives are merely pretending to be 'ordinary chaps':

(55) I should make it clear that Arnold was not in any crude sense 'spoilt' by success. He was no tax-dodger with a yacht and a house in Malta. ... He lived in a fairly large, but not immodest suburban villa in a 'good class' housing estate in Ealing. His domestic life was, even to an irritating extent, lacking in style. It was not that he put on an act of being 'the ordinary chap'. (Murdoch 1975: 31)

Narrators may produce a negative inferential when they wish, sincerely or manipulatively, to introduce an interpretation of an aspect of the context which they want to reject.

However, some examples contain information which is not likely to be inferred by the hearer from the local context. The negative inferential acts as an instruction to the hearer to establish and then reject an inferential connection (eg. explanation, conclusion, etc.) with the local context.

Why would a speaker mention a proposition which is unlikely to be inferred by the hearer only to reject it immediately? To amuse and disarm, as in the following e-mail message from the chair of my department:

(56) Be sure to let me know when you are out of town on University business. It isn't only that I'm nosey. Apparently for Worker's Compensation coverage in case of an accident, we have to know you're on the job. (P. Cowell, C.S.U. English dept. e-mail message 4/19/93)

More interestingly, because the form reveals inferences made by its speaker, it can be used by authors to reveal the thoughts of a fictional character or narrator. Several of my examples (e.g. (50)) are produced by the narrator of Murdoch (1975) and help to undermine his reliability. ${ }^{14}$

\section{Inferentials: An analysis}

The hypothesis to be explored here is that the inferential can be viewed as a pragmatic instruction to its audience to regard its clause as an interpretation of its local context, that is, to be about, rather than of, its context. The specific interpretations, described in section 4 , are to be seen as particular interpretations of particular contexts. Consider the following pair:

\footnotetext{
${ }^{14}$ Whether relevance as opposed to truth is always at issue with inferentials will be dealt with in the next section. Certainly (47) and (50) demonstrate that truth per se is not always at issue.
} 
(57) a. Women in Ireland are not a form of prayer.

b. It is that women in Ireland are not a form of prayer.

(57a) merely reports that women in Ireland are not a form of prayer; (57b) on the other hand, invites the inference that the proposition women in Ireland are not a form of prayer has some special relevance to the local text. Utterances seem in general to have two very distinct types of roles in discourse: They can be either contextually or metacontextually relevant. That is, they can fit with their contexts in ways which we might characterize as ordinary, e.g., adding information, or they may have an extraordinary relevance by commenting on their contexts. In this section I will account for the strictly local relevance of inferentials, and argue that their interpretation involves two stages. The first stage involves the interpretation of the inferential construction as a generalized conversational implicature licensed by the construction's form, namely that the proposition represented by the clause is an interpretation of the local context. The second stage involves calculating the potential particularized implicatures of a construction in its specific context; that is, calculating just how the inferential might be an interpretation of its specific context.

That the inferential relates to the local context follows from Grice's CP, which requires that a participant's contribution 'be such as is required at the stage at which it occurs,' from the submaxim of manner "Be orderly," and from the fact that there is nothing to indicate that the sentence has a non-local relevance. Any speaker/writer intending a non-local relevance would be in violation of the submaxim of manner "Avoid obscurity." Note, of course, that although the inferential interprets the immediately prior text (or immediate context, in the case of Japanese), the extent of that text (or context) is not fixed. This is another source of the indeterminacy of the meaning of inferentials.

In support of the claim that the construction, because of its form, licenses a generalized conversational implicature, note that such implicatures are detachable and calculable (Levinson 1983: 128). ${ }^{15}$

As we have seen from the data presented in this paper, inferential sentences, whether positive or negative, interrogative or modalized, all instruct their hearers to regard the clause as an interpretation of the local context; that is, the same general inference follows from all inferentials.

This inference can be detached, as is generally the case with implicatures dependent upon the form of the utterance. If we remove the matrix, we may lose the inferential interpretation. Compare (57a) and (57b).

The inferential effect can be calculated as there are just two ways in which

\footnotetext{
${ }^{15}$ Usually, conversational implicatures are cancellable. However, it seems to me that a speaker producing an expression whose form would ordinarily license an implicature is unlikely to be believed if they claimed that the form has no relevance at all. For example, a parent who spells a message out to a spouse in the hearing of a preliterate child can hardly deny that they do so with some intention, such as that of excluding the child from the intended audience. Likewise, the generalized conversational implicature licensed by the inferential construction seems not to be cancellable. In this respect it is like a conventional implicature, and may in some languages, such as Japanese, perhaps, have become conventionalized. However, if the construction licensed conventional rather than conversational implicatures, we could not explain how it licenses the same implicatures in language after language.
} 
a new proposition is integrated with those that have gone before it: It can have either ordinary or extraordinary relevance. That is, its relevance can only be either contextual or metacontextual. The calculation might go as follows.

A speaker has used an inferential such as $(57 \mathrm{~b})$ whose conventional meaning is the same as that of the corresponding non-inferential (57a).

So, given a choice between (57a) and (57b), why would a speaker choose the expression consisting of a that clause subordinated to semantically empty it and be?

(57b) cannot mean just (57a) because this would violate the maxim of manner, specifically the injunction to be brief. It would also violate the maxim of relation, as the matrix would have no relevance.

Nor can (57b) convey less than (57a) because (57a) represents the conventional meaning of $(57 \mathrm{~b})$, the minimal information represented by both. If (57b) meant less than (57a), a hearer could not work out the significance of (57b) because the matrix, having no conventional meaning, gives hearers no clue as to what information in (57b) to disregard. So a speaker using (57b) to convey less information than (57a) would be in violation of the maxim of manner's injunction against obscurity.

It follows that (57b) must have more significance than (57a). This extra significance cannot be conventional because if it were the speaker would be being obscure and so in violation of manner, and perhaps also in violation of quantity in not supplying sufficient information for the circumstances, as we are given no clues as to what that conventional extra might be.

Consequently, the extra significance associated with (57b) must have to do with the relationship of the information represented in it to its context, i.e. its relevance, because, ex hypothesi, there are only two possibilities: Either the proposition represents information that is integrated into the interpretation of the text as ordinarily topical, or it has some special, extra relevance. It is relevant as information about the context.

Significantly in this regard, because its interpretation crucially involves the maxim of relation, it is the proposition's relevance, rather than its truth, which is important in the context. Example (50) pointedly illustrates this characteristic. Negative inferentials deny, not the truth, but the (special) relevance of the proposition represented by an inferential's clause. Truth, although necessary for relevance, is certainly not sufficient.

In sum, the generalized conversational implicature of the inferential is that the clause represents an interpretation of the local discourse context.

On the other hand, the further interpretation of the clause as a reflection, explanation, conclusion, etc., must be derived from the interpretation of the inferential as a comment on the context, and the particulars of that context, in accordance with Grice's CP and maxims. In other words, this interpretation consists of a set of particularized conversational implicatures. They are particularized solutions to the problem of discovering the specific special relevance of a particular inferential sentence in a particular context. They have the characteristics of such implicatures: They are vague and must be calculated, as Grice claimed. They are also defeasible: The audience can never be certain that the particular implicatures they derive are the ones intended, and consequently any particular inferences can be denied.

Finally, the construction appears to have the same or very similar 
interpretations in all the languages in which it occurs. This universality can only result from universal principles of pragmatic interpretation, such as the $\mathrm{CP}$ and maxims. It follows that the interpretations of inferentials must be non-conventional.

If we assume that hearers draw inferences as they create meanings, and if we also assume that a speaker's goal is to ensure that the hearer entertains only the interpretation he or she intends, then we can view the inferential form as an instruction to the audience to infer an interpretational relationship between the clause and the local context. If the inferential contains matrix negation then it indicates that an inference which may be plausible in the context is not intended by the narrator. The adverbs and modals which occur in many inferentials indicate the scope of the relevance of the inferential propositions and the degree of faith the speaker has in them.

\section{Conclusion}

What inferentials do is indicate that the clause is to be regarded as an interpretation of the local context. Negative inferentials deny the interpretation; positive inferentials affirm it; and inferentials with adverbs or modals indicate the degree of confidence to be placed in the interpretations. This function of the inferential is to license a generalized conversational implicature which is consequently the responsibility of the speaker.

Inferentials conversationally license the particularized inferences that the clause is (or is not) a conclusion, account, explanation, reason, possibility, reflection, etc. The choice amongst these inferences is the responsibility of the hearer.

The interaction between interpretations for which the speaker is responsible and interpretations for which the hearer is responsible can give the impression that the speaker appears to be making assumptions about inferences being made by the hearer in the interpretive process. By revealing what the speaker appears to think that the hearer assumes, the construction can be used by skilled writers to reveal the concerns of narrators, sometimes to suggest their limitations and unreliability.

Given that a speaker must guide an audience along an interpretational path, licensing certain inferences and rejecting others, it should not be surprising that languages provide specialized sentence structures whose function is to indicate interpretations of local context. Nor should it be surprising to find that these constructions occur in identifiable discourse patterns designed specifically to indicate that the speaker wants the hearer to draw, not this inference, but that other one. And, given the universality of the pragmatic principles upon which the inferential construction relies, it is not surprising either that the construction has the same functions across languages.

\section{References}

Austen, J. (1963) [1813] Pride and prejudice. London: Dent.

Austen. J. (1980) [1818] Persuasion. Oxford: Oxford Paperbacks. 
Bradley, M.Z. (1982) The mists of Avalon. New York: Ballantine.

Collins, P.C. (1991) Cleft and pseudo-cleft constructions in English. London: Routledge.

Declerck, R. (1988) Studies on copular sentences, clefts and pseudo-clefts. Louvain: Leuven University Press.

Declerck, R. (1992) The inferential it is that-construction and its congeners. Lingua 87: 203-230.

Delahunty, G.P. (1982) Topics in the syntax and semantics of English cleft sentences. Bloomington: IULC.

Eco, U. (1988) Il pendolo di Foucault. Milano: Bompiani.

Eco, U. (1989) Foucauld's pendulum. Translated by W. Weaver. San Diego: Harcourt, Brace, Jovanovich.

Frame, R. (1981) Colonial Ireland 1169-1369. Dublin: Helicon.

Garrett, G. (1983) The succession. New York: Doubleday.

Gogarty, O.St.J. (1968) As I was going down Sackville Street. London: Sphere.

Grice, H.P. (1975) Logic and conversation. In P.Cole and J.L. Morgan (eds.), Syntax and semantics: Speech acts. Vol. 3. New York: Academic Press.

Horn, L.R. (1989) The natural history of negation. Chicago: University of Chicago Press.

Irving, J. (1978) The 158-pound marriage. New York: Pocket Books.

Kies, D. (1988) Marked themes with and without pronominal reinforcement: Their meaning and distribution in discourse. In E. Steiner and R. Veltman (eds.), Pragmatics, discourse and text. Norwood: Ablex.

Kuno, S. (1973) The structure of the Japanese language. Cambridge, MA: MIT Press.

Levinson, S. (1983) Pragmatics. Cambridge: Cambridge University Press.

Mallory, J.P. (1989) In search of the Indo-Europeans. London: Thames and Hudson.

Murdoch, I. (1975) The black prince. New York: Penguin.

Powell, T.G.E. (1983) The Celts. London: Thames and Hudson.

Quirk, R., S. Greenbaum, G. Leech, J. Svartvik (1985) A comprehensive grammar of the English language. London: Longman.

Richter, M. (1988) Medieval Ireland. Dublin: Gill and Macmillan.

Rosch, E. (1975) Cognitive representations of semantic categories. Journal of Experimental Psychology: General 104: 192-233.

Schneider, S.H. (1989) The changing climate. Scientific American (Sept.).

Somerville, E. and M. Ross (1977) The real Charlotte. London: Quartet. 


\section{Gerald P. Delahunty}

Sperber, D. and D. Wilson (1986) Relevance: communication and cognition. Cambridge, MA: Harvard.

Wilder, T. (1987) The ides of March. New York: Harper and Rowe. 